\title{
Engaging Pre-Clerkship and Clerkship Students as Medical Scribes in the Emergency Department
}

\author{
Abanoub Aziz Rizk $^{1}$ | Ahmed Al-Izzi ${ }^{2}$ | Naitik Acharya ${ }^{3}$ | Liam H \\ Brown $^{4}$ | Gina Rizq ${ }^{5}$ | Samuel Gobraeil ${ }^{3}$ | Hanifa J Soueid 4
}

${ }^{1}$ University of Ottawa Faculty of Medicine

2 University College Cork Faculty of Dentistry, Cork, Ireland

3 University of Guelph Department of Biomedical Sciences

4 University of Guelph Human Health and Nutritional Sciences

${ }^{5}$ Royal College of Surgeons in Ireland, Faculty of Medicine Health Sciences

\section{Correspondence}

Abanoub Aziz Rizk

Email: abanoub.aziz.rizk@gmail.com

\section{Publication Date}

February 7, 2022

MJM $2022(20) 23$

https://doi.org/10.26443/mjm.v20i1.913

\section{Ф் McGill Journal of Medicine}

www.mjmmed.com

\section{c) (ㅇ)(2)}

This work is licensed under a Creative Commons BY-NC-SA 4.0 International License.

\begin{abstract}
The Emergency Department (ED) is a highly stressful and fast-paced environment in which doctors are challenged to efficiently adapt and recall knowledge to make safe patient-care decisions. This commentary discusses the benefits of exclusively hiring pre-clerkship and clerkship medical students as medical scribes in the emergency department. A total of twenty-eight (28) articles and studies are explored and used to reflect upon the benefits of scribing implementation in medical education. These include, but are not limited to, increasing medical student exposure to the specialty of emergency medicine, enhancing their clinical skills, and assisting students to pay-down their medical school-related debt. Furthermore, appointing medical students as scribes is mutually beneficial to the ED by helping to cut down the lengthy wait times for patients and reduce the significantly high rates of emergency physician burnout. We conclude that hiring medical students as scribes in the ED is a potentially beneficial practice that merits further consideration and analysis.
\end{abstract}

\section{KEYWORDS}

pre-clerkship student, clerkship student, medical scribe, emergency department (ED), patient-doctor interaction

\section{1 | INTRODUCTION}

Physician burnout, the feeling of emotional and physical fatigue from excessive work hours, has been on the rise for many years. (1) The rise in involvement of medical scribes in the healthcare field has decreased documentation time and assisted in lowering such physician burnout. (2) A medical scribe is a trained individual 
whose role is to concurrently document pertinent medical information during a patient-physician encounter. (3) Due to limited scribing positions, it is more difficult for medical students to secure clinical placements when competing against scribes in certain departments, such as the Emergency Department (ED). (2) The erratic environment, high student interest, fast-paced acute setting, and limited availability of resources have rendered the ED one of the most sought-after fields to gain experience in. (4) This article reflects on what is gleaned from the literature to support the conclusion that hiring more medical students as medical scribes can assist in tackling the multiple concerns raised.

\section{2 | BENEFITS FOR MEDICAL STUDENTS}

\section{1 | Financial Benefits}

Medical students are facing a huge burden due to the cost of medical education over their academic and training years, and many graduate with overwhelming amounts of debt. $(5,6)$ The anxiety of debt amongst medical students has an adverse effect on their overall wellbeing and academic performance. (7) Debt is correlated with poor academic performance, increased stress levels, and adverse effects on mental health. (7) Finances remain the second most common contribution to stress reported by medical students, right behind coursework. (7) It is crucial to mitigate the financial burden students carry to improve their wellbeing and success in medical school.

As medical record-keeping is shifting from paperwork to computers, scribing employment is growing across North America. (8) Hiring medical students as medical scribes presents an opportunity to ease the financerelated stress. Summer and part-time scribing jobs can allow medical students to earn income while balancing their rigorous coursework. (9) However, the responsibilities of the scribing job could also add to the preexisting stress from coursework. Scribing companies also seek out medical students requiring part-time employment because they have an increased chance of training suc- cess. (8) Moreover, medical students are likely to reduce the cost and time dedicated to scribe training because of their background and experience, thus benefiting the hiring companies. (9)

\section{2 | Increased Exposure to Emergency Medicine}

Throughout their education, medical students require ample exposure to the emergency department, and yet, they have reported experiencing otherwise. (10,11) In a retrospective analysis, none of the 75 final-year medical students covered all the curriculum's recommended training categories. (11) Many explained that they were insufficiently exposed to patients in the emergency room, which raises the concern that medical students are not receiving adequate exposure and training in the emergency department. (11) Hiring medical students as medical scribes enables them to strengthen their skillset and enhance the quality of care, while increasing medical student exposure to the emergency department. $(12,13)$

As part of developing their professional abilities, medical students must train in interprofessional collaboration, enhance their communication and organizational skills, and learn to recognize patterns. (12,13) Working as a scribe will allow students to achieve this while being actively involved in the day-to-day routine of an emergency department physician. (12) In contrast to observerships and shadowing experiences, students working as medical scribes are challenged to strategically summarize the details of the patient encounter. $(12,14,15)$ This enables them to enhance their familiarity with medical terminology and standard procedures in the emergency room. (15) Additionally, the students will experience doctor-patient and doctor-family interactions that will increase their competency in historytaking and their communication skills. (14) Therefore, medical students will gain valuable insight into emergency medicine and understand how to think like a doctor. (12)

Medical students working as medical scribes in the emergency department will serve to benefit both the 
students and the medical practices in which they work. As a result, this will increase medical students' exposure to the emergency department and establish the reliability and confidence of the next generation of physicians.

\section{3 | BENEFITS OF HAVING MEDICAL SCRIBES}

\section{1 | Increased Access to Medical Scribes}

The use of medical scribes in hospitals has become increasingly popular over the last few years. According to the American College of Medical Scribe Specialists, the number of working medical scribes in the United States has increased from 20,000 in 2015 to a projected 100,000 by the end of 2020; roughly allowing 1 in every 9 physicians to have access to a medical scribe when practicing. (16) However, even with the drastic yearly increases in medical scribe employment, the vast majority of physicians still do not have access to a medical scribe. (16)

A major factor pertaining to why the use of medical scribes has not become ubiquitous within physician practice relates to a lack of desirability associated with medical scribing as a full-time vocation. It has been reported that medical scribes make roughly USD $\$ 15-25$ per hour, work long hours, and work in an intense and stressful environment. $(2,17)$ As such, the merits of a medical scribe job alone are often not enough to convince people to get the necessary training and commit to being a medical scribe long-term. For medical students, there are numerous subjective benefits that increase the desirability of being a medical scribe, although, it does not reduce the large rate of turnover associated with the scribing profession. $(2,8)$

Additionally, it has been shown that training medical students as medical scribes may be the most economically viable option. A study found that a comparison of 3 groups of students (medical students, pre-medical students, alternative background unrelated to medicine) showed medical students were the most efficient to complete the medical scribe training by a significant margin. (8)

\section{2 | Reducing Emergency Department Wait Times}

Studies have shown that ED overcrowding is widespread in most Canadian and American cities. (18) Lengthier wait times in the ED not only puts the patients' health at risk, but it reduces patient satisfaction and leads to overcrowding in the emergency room. (19) In a research study conducted by the Canadian Institute for Health Information (CIHI) it was demonstrated that, in 2018-2019, patients who visited the ED spent an average of 3-4 hours upon receiving their primary assessment. (20) However, $90 \%$ of these visits resulted in the patients spending up to 10.9 hours in total. (20) Hiring medical scribes in the emergency department enhances patient-physician interactions, increases patient satisfaction, allows for better distribution of administrative tasks, and improves workplace flow. (14) According to Scribe America, medical scribes generate noteworthy improvements in doctors' feedback and the accuracy of the medical charts. (21) This enables the physician to assess and treat more patients in less time and increases their productivity by up to $13 \%$. $(22,23)$ Furthermore, a direct correlation has been observed between the implementation of medical scribes and a reduction of clinical wait times.

Medical scribes play a significant role in improving patient experience by allowing for more valuable clinician interaction with patients and resulting in more accurate and organized patient records. (14) Thus, the implementation of medical students as medical scribes would considerably reduce the stress and workload of the fastpaced environment of the emergency department on physicians, while potentially reducing wait times.

\section{3 | Relieving Overworked Emergency Care Physicians}

The rise of clerical burden is a major driving force for the increased emergency department physician burnout rate. (24) Causal of this trend is the transition towards Electronic Medical Records (EMR), that can provide clinicians with flexibility at work but add to the continuous 
number of hours of work past their shift. (24) The introduction of EMR without creating space to preserve the energy of those who manage the medical system leads to increased physician burnout, as well as a drop in both productivity and patient satisfaction. (24) EMR requires efficient navigating skills in addition to the other skills that physicians have to acquire proficiency in as a part of their training. (25) Moreover, EMR are prone to failure (system crash, errors at entry in medication lists, and examination findings) resulting in an additional stressor in the ED. $(9,24)$ Many physicians have agreed that the integration of medical scribes into the medical team alleviates work stress as it allows them to focus on patient interaction and increases patient satisfaction. (12) With the decline in physicians' energy, efficiency, and overall mental health, the introduction of medical scribes reduces the burden on physicians created by EMR documentation. (12,24)

When medical students are given the opportunity to aid physicians by scribing, they acquire the logic of medical decision-making due to the exposure to different scenarios and makes pattern recognition become second nature. (12) Furthermore, using EMR repetitively in medical practice allows medical students to recognize incidents of miscommunication and learn where mistakes can happen in order to prevent them in the future. (12) Medical student scribing also provides an opportunity for mentorship of students who will later lead the medical field, and through this relationship, students can learn effective patient-physician communication and build their clinical style. (12) Making use of medical student scribes is a measure of clinical care redesign that is mutually beneficial for both parties.

\section{4 | CHALLENGES OF IMPLEMENT- ING SCRIBES IN THE EMER- GENCY DEPARTMENT}

While healthcare systems are rapidly hiring scribes for licensed clinicians as a means of potentially decreasing physician burnout and patient documentation time, this can introduce certain complications to those aspiring to become successful MD candidates. $(2,24,26)$ The main reason behind overcrowding in the ED is due to too many patients being admitted, and thus, scribing could potentially have a very little effect on the wait times.

Increasing prevalence of scribes in hospitals and private clinics might lead to the rise of overall competitiveness of medical school applications. $(2,24)$ For instance, medical scribing in the US is quickly becoming the norm for many pre-medical applicants and is strongly suggested by various medical school admission committees. (2) To enroll as a scribe in the United States, students are required to either complete a minimum of 120 hours of clinical training or partake in 40-hour courses containing EMR modules. $(2,26)$ Given those requirements, the majority of clinicians prefer hiring scribes who are going to be willing to work with them full-time for a minimum period of 6-12 months, which will present challenges to pre-medical and medical students due to lack of time, commitment, as well as inability to handle such hefty responsibilities while carrying out their primary role as a medical student. $(2,9)$

Additionally, most medical schools prefer choosing applicants who have strong exposure to medical and clinical settings prior to enrollment in their programs. $(2,9)$ The increased exposure that some applicants will have with scribing experience may lead to higher expectations and admission barriers for future applicants. $(2,9,24)$ Scribing would also emerge as a perceived benefit or even be considered as a "hidden pre-requisite" that can eventually blend in with medical school application. $(2,9,24)$ It is important to prevent introducing unintended consequences of hiring students as scribes. It is not the goal to deter students from applying for scribe occupations, but to rather avoid unintentional consequences of scribing experience from evolving into a "hidden pre-requisite". $(2,9,24)$

A pilot study showed that hospitals' grants paid the scribes in Canada, whereas in the US, the scribes are paid by the physicians, although it may vary depending on location. (27) In other public scribing models, such as Australia, students reported that they benefited from the experience and complemented their medical school education. (28) Whereas the US-based scribing models 
focus more on the financial aspect of benefits. (28) The benefits of scribes are transferable in both public and private healthcare systems; however, more research is needed to examine different scribing models and how they are funded. (27)

\section{5 | CONCLUSION}

Through this commentary, we reflect on what is gleaned from the literature to support the conclusion that hiring more medical students as medical scribes can assist in tackling long wait times in the ED and physician burnout. Although such initiatives can begin tackling these aforementioned concerns, a collaborative effort is required across faculties to implement scribing programs to ensure medical students can gain financial and educational benefits. Considering the diverse healthcare models and funding systems in different countries, this may prove to be a challenge to implement. Having said that, the benefits of supporting students financially, increasing exposure to the field of emergency medicine, supporting attending physicians, and decreasing patient wait times are all possibilities worth exploring with further studies and initiatives.

\section{REFERENCES}

1. The Lancet. Physician burnout: a global crisis [Internet]. Vol. 394, The Lancet. Lancet Publishing Group; 2019 [cited 2021 Jun 18]. p. 93. Available from: https://www.

2. DeWitt D, Harrison LE. The Potential Impact of Scribes on Medical School Applicants and Medical Students with the New Clinical Documentation Guidelines. J Gen Intern Med [Internet]. 2018 Nov 1 [cited 2021 Jun 10];33(11):2002-4. Available from: https://pubmed.ncbi.nlm.nih.gov/30066114/

3. Home - Medical Scribes of Canada [Internet]. [cited 2021 Jun 18]. Available from: http://www.medicalscribesofcanada.ca/

4. Penciner R. Emergency medicine preclerkship observerships: Evaluation of a structured experience. Can J Emerg Med [Internet]. 2009 [cited 2021 Jun 18];11(3):235-9. Available from: https://pubmed.ncbi.nlm.nih.gov/19523272/

5. Kwong JC, Dhalla IA, Streiner DL, Baddour RE, Waddell AE, Johnson IL. Effects of rising tuition fees on medical school class composition and financial outlook. CMAJ. 2002;166(8).

6. Steinbrook R. Medical Student Debt - Is There a Limit? N Engl J Med [Internet]. 2008 Dec 18 [cited 2021 Jun 10];359(25):2629-32.
Available from: https://pubmed.ncbi.nlm.nih.gov/19092148/

7. Pisaniello MS, Asahina AT, Bacchi S, Wagner M, Perry SW, Wong $\mathrm{ML}$, et al. Effect of medical student debt on mental health, academic performance and specialty choice: A systematic review [Internet]. Vol. 9, BMJ Open. BMJ Publishing Group; 2019 [cited 2021 Jun 10]. p. 29980. Available from: http://bmjopen.bmj.com/

8. Walker KJ, Dunlop W, Liew D, Staples MP, Johnson M, Ben-Meir $M$, et al. An economic evaluation of the costs of training a medical scribe to work in Emergency Medicine. Emerg Med J [Internet]. 2016 Dec 1 [cited 2021 Jun 10];33(12):865-9. Available from: https://pubmed.ncbi.nlm.nih.gov/27352788/

9. Lowry JE. MEDICAL STUDENTS' PERSPECTIVES ON THEIR EXPERIENCES AS MEDICAL SCRIBES. 2017.

10. Healy S, Tyrrell M. Stress in emergency departments: Experiences of nurses and doctors [Internet]. Vol. 19, Emergency Nurse. RCN Publishing Company Ltd.; 2011 [cited 2021 May 14]. p. 31-7. Available from: https://pubmed.ncbi.nlm.nih.gov/21877616/

11. Shaban S, Cevik AA, Canakci ME, Kuas C, El Zubeir M, Abu-Zidan F. Do senior medical students meet recommended emergency medicine curricula requirements? BMC Med Educ [Internet]. 2018 Jan 5 [cited 2021 May 14];18(1):8. Available from: https://bmcmededuc.biomedcentral.com/articles/10.1186/s12909017-1110-1

12. Abdulahad D, Ekpa N, Baker E, Foley KA, Fogel B, Troy, et al. Being a Medical Scribe: Good Preparation for Becoming a Doctor. Int Assoc Med Sci Educ [Internet]. 2020 [cited 2021 May 14]; Available from: https://doi.org/10.1007/s40670-020-00937-w

13. O'Keeffe C, Carter A, Mason S. The value of emergency medicine placements for postgraduate doctors: Views of Foundation Year 2 doctors and training leads in the emergency department (ED). Postgrad Med J [Internet]. 2017 Jan 1 [cited 2021 May 14];93(1095):15-9. Available from: https://pubmed.ncbi.nlm.nih.gov/27307472/

14. Eley RM, Allen BR. Medical scribes in the emergency department: The scribes' point of view. Ochsner J [Internet]. 2019 Dec 1 [cited 2021 May 14];19(4):319-28. Available from: /pmc/articles/PMC6928660/

15. Gharahbaghian L, Hindiyeh R, Langdorf MI, Vaca F, Anderson CL, Kahn JA, et al. The effect of emergency department observational experience on medical student interest in emergency medicine. J Emerg Med. 2011 Apr 1;40(4):458-62.

16. Gellert GA, Ramirez R, Webster SL. The rise of the medical scribe industry: Implications for the advancement of electronic health records [Internet]. Vol. 313, JAMA - Journal of the American Medical Association. American Medical Association; 2015 [cited 2021 Jun 10]. p. 1315-6. Available from: https://pubmed.ncbi.nlm.nih.gov/25504341/

17. Hafer J, Wu X, Lin S. Impact of scribes on medical student education: A mixed-methods pilot study. Fam Med [Internet]. 2018 Apr 1 [cited 2021 Jun 10];50(4):283-6. Available from: https://pubmed.ncbi.nlm.nih.gov/29669146/ 
18. Trzeciak S, Rivers EP. Emergency department overcrowding in the United States: An emerging threat to patient safety and public health [Internet]. Vol. 20, Emergency Medicine Journal. BMJ Publishing Group; 2003 [cited 2021 Jun 19]. p. 402-5. Available from: https://pubmed.ncbi.nlm.nih.gov/12954674/

19. Understanding Emergency Department Wait Times । Colleaga [Internet]. [cited 2021 Jun 19]. Available from: https://www.colleaga.org/article/understanding-emergency-

department-wait-times 20. National Ambulatory Care Reporting System metadata (NACRS) | CIHI [Internet]. [cited 2021 Jun 19]. Available from: https://www.cihi.ca/en/national-ambulatory-carereporting-system-metadata-nacrs

21. ScribeAmerica - Medical Scribe Program for Doctors, Hospitals Eds [Internet]. [cited 2021 Jun 19]. Available from: https://www.scribeamerica.com/

22. Walker KJ, Ben-Meir M, Phillips D, Staples M. Medical scribes in emergency medicine produce financially significant productivity gains for some, but not all emergency physicians. EMA - Emerg Med Australas [Internet]. 2016 Jun 1 [cited 2021 Jun 19];28(3):262-7. Available from: https://pubmed.ncbi.nlm.nih.gov/26954293/

23. Taylor KA, McQuilkin D, Hughes RG. Medical Scribe Impact on Patient and Provider Experience. Mil Med [Internet]. 2019 Apr 2 [cited 2021 Jun 19];184(9-10):388-93. Available from: https://pubmed.ncbi.nlm.nih.gov/30811535/

24. Abelev I, Fraser J, Canales DD, Hanson N, Atkinson $P$, Lewis D. Medical and Undergraduate Student Perceptions on Scribing in an Emergency Department. Cureus [Internet]. 2021 Mar 12 [cited 2021 Jun 10];13(3). Available from: https://pubmed.ncbi.nlm.nih.gov/33859895/

25. Bell SK, Delbanco T, Elmore JG, Fitzgerald PS, Fossa A, Harcourt $\mathrm{K}$, et al. Frequency and Types of Patient-Reported Errors in Electronic Health Record Ambulatory Care Notes. JAMA Netw Open [Internet]. 2020 Jun 9 [cited 2021 Jun 18];3(6):205867. Available from: https://jamanetwork.com/

26. Rich $\mathrm{N}$. The impact of working as a medical scribe [Internet]. Vol. 35, American Journal of Emergency Medicine. W.B. Saunders; 2017 [cited 2021 Jun 10]. p. 513. Available from: http://www.ajemjournal.com/article/S0735675716309202/fulltext 27. Graves, P. S., Graves, S. R., Minhas, T., Lewinson, R. E., Vallerand, I. A., Lewinson, R. T. Effects of medical scribes on physician productivity in a Canadian emergency department: a pilot study. CMAJ Open [Internet]. 2018 [cited 2021 Oct 15];6(3), E360-E364. Available from: https://pubmed.ncbi.nlm.nih.gov/30181347/

28. Cabilan CJ and Eley, R. The potential of medical scribes to allay the burden of documentation and enhance efficiency in Australian emergency departments. Emergency Medicine Australasia [Internet]. 2016 [cited 2021 Oct 15];27(6):207-211. Available from: https://link.springer.com/article/10.1007\%2Fs11606$018-4582-8$ 